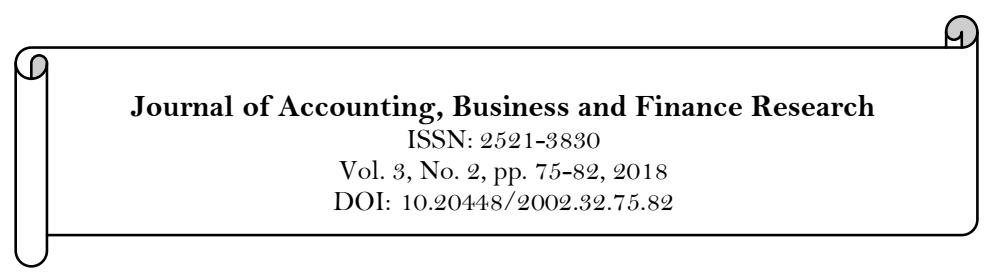

Cupdates

\title{
A Study of Organizational Factors and Employee Retention: The Case of Ministry of Civil Service in Oman
}

\author{
Ibrahim Rashid Humaid Al Shamsi ${ }^{1 *}$ \\ Salim Alsinani ${ }^{2}$
}

${ }^{1}$ Al Buraimi University College, Oman.

Email: ibr1166@hotmail.com

${ }^{2}$ Ministry of Civil Service, Oman.

Email: salim alsinanizs@hotmail.com

\begin{abstract}
Retaining a skilled workforce and decreasing unwanted employee turnover is an economic and service delivery necessity for organizations. A number of researchers have studied job satisfaction, as well as employee turnover relationship with regards to employee retention. The present study builds on these from a different perspective by examining employee perceptions of organizational factors that influence on employee retention. This study examined the relationship between employee retention, and core elements of organizational factors which includes organizational leadership, organizational policies, communication, team working relationships, organizational commitment. The results revealed greater insights into the organization factors and employee retention relationship, as well as it provides empirical validation of this relationship in the context of the ministry of civil service in Oman.
\end{abstract}

Keywords:

Human resource management Human resource development Organizational factors

Employee retention Employee turnover.

Licensed:

This work is licensed under a Creative Commons Attribution 4.0 License.

Publisher:

Scientific Publishing Institute

\section{Introduction}

The workplace dynamics has been experiencing constant changes in recent decades. The working environment gives an infinitesimal picture of the everyday existences of employees who come to work, carry out their responsibilities within the confines of organizational structures. Any individual who has ever been in the workplace can confirm the way that employees are shaped by external influences and lives inside multitudinous storylines take place, and change, on any given day or time of the day. This is the workplace reality, fundamentally the same as the storylines of soap operas, only in real life settings, except that these are real-life settings. The workplace includes a variety of employees with various interests, identities, and ways of life that meet up for a typical reason. The workplace can be warm and cordial, or chilly and foreboding or it can be a blend of both.

Thus, employees are quickly being perceived as one of the basic elements in the formulation of organizational strategies in the management system of organizations in general. All the more important, every organization wants to become dynamic and growth-oriented. To succeed in a rapidly-changing environment, organizations need talents. Organizations can become dynamic and develop only when employee abilities are consistently honed and utilized. Talented employees assume an indispensable part in progress and development of every organization. Consequently, employee retention is considered as an essential component within an organization's strategic human resource management strategies. It starts with recruiting the right individuals who are wholeheartedly committed to the organization. Henceforth, employee retention is established in in core organizational factors, and a comprehension of these factors elucidates the real human resources management practices that influence employee retention.

Present day Omani managers are still in a developing stage, yet, it is expected that the economy of Oman will achieve a functioning time of advancement sooner rather than later with reference to the Oman vision 2020 plan. In any case, Omani business visionaries have begun to understand that employees are a basically 
vital asset in Oman. A skilled Human Resources Development (HRD) department in any institution is the apparatus for the change of the organization's efficiency and maintains positive relations with collaborators. The advancement of Omani Human Resources Management (HRM) has been developing from conventional to present day. To maintain authority in HRM practices there is a challenge whereby the traditional role of the HRM is controlled by the public. Up till now, current HRM in Oman is still in the beginning periods of change. Employee turnover is a ratio comparison of the number of employees the institution must replace in a given period to the average number of total employees. A huge concern for most organizations, employee turnover is a costly expense especially in lower paying job roles, for which the employee turnover rate is highest. Many factors play a role in the employee turnover rate of any organization, and these can stem from both the employer and the employees.

It is imperative that organizations understand the factors that influence employee retention. A study by Islam and Ismail (2008) on employee motivation in Malaysia stated that the average company loses approximately $\$ 1$ million with every ten managerial and professional employees who leave the organization and combined with the direct and indirect costs; the total cost of an exempt employee's turnover is a minimum of one year's pay and benefits. In the last decade, there has been a shift in employee behaviour, with more employees moving from the public sector to the private sector in Oman. As such, the public sector, and more specifically, the Ministry of civil services in Oman, is losing some of their most skilled and talented employees to the private sector. Employee retention is one of the greatest challenges that the Ministry of civil services in Oman currently faces. This has given rise to various issues within the Ministry, including scenarios whereby unskilled managers are working in the wrong departments within the Ministry. These workers make decisions which often lead to mistakes at work, and lost time in correcting these mistakes. In order to provide high quality services to the public, the Ministry needs to maintain an adequate number of well-trained employees, in all departments.

As this problem is only now becoming known, there has been limited research on this issue, especially in Oman. In fact, there are some quarters who believe that there is no problem and that the migration of employees from the public sector to the private sector is good as it is working towards developing the country. While reviewing the research on this phenomenon in Oman, several writers have evaluated the issue of barriers to human resources development in the public sector in Oman with an emphasis on religion, localization policy in Oman and its implications for HRM and the voluntary turnover in the Omani public sector. However, there appears to be no research done specifically dealing with the influence of organizational factors on the retention of employees. This is troubling as if this phenomenon is not investigated and averted, the public institutions will end up with no professional labour and the researcher also wonders what would happen within the next ten years and how the government will address this problem.

This study attempts to fill this research gap by empirically investigating the influence of organizational factors on the retention of employees in the Ministry of Civil Service in Oman. In doing this, the objective of this paper would be met.

\section{Literature Review}

I the recent decades, the HRM literature has moved from a micro focus on individual HRM practices to a debate on how HRM as a more all-inclusive management approach may contribute to the competitive advantage of organizations. Various studies have attested that managing employee turnover is a challenge for organizations, as different institutions are using different approaches to retain employees (Sinha \& Sinha, 2012).

An organization that is unable to retain its employees will not be able to capitalize on human assets developed within the organization (Shekshnia, 1994). Thus, various scholars have argued that employee retention activities are a vital human resource strategy. Through a detailed literature survey, the different organizational factors that influence employee retention in have been determined. They are; leadership, organizational policies (culture and structure), communication, team working relationships, organizational commitment. They are discussed in the following subsections

\subsection{Organizational Leadership}

Organizational leadership is characterized as the conduct of an employee that results in non-coercive impact when that employee is coordinating and organizing the activities of a group towards the achievement of a mutual objective (Bryman, 1992). Organizational leadership is conceptualized as far as four tasks that should be accomplished in any organization: giving guidance, guaranteeing arrangement, building commitment, and confronting adaptive challenges (Chitsaz-Isfahani \& Boustani, 2014). Leaders are integral to the development of organizational cultures, societal systems, frameworks and structures that encourage knowledge creation, sharing and development (Muleya, Ngirande, \& Rachidi, 2016).

A number of research scholars have highlighted the positive impact of transformational leaders in organizational outcomes which brought about brought reduced employee turnover, and increased organizational behaviours (Salisu, Chinyio, \& Suresh, 2017) and prompted more grounded institutional commitment (Salisu et al., 2017). Along these lines, in light of the literature review, it gives the idea that 
organizational leadership has a positive influence on employee retention.

\subsection{Organizational Policies}

Organizational policies in this context, comprise corporate organizational culture and structure. Corporate culture is portrayed as the imperceptible powers that shape life in an organization (Fitz-enz, 1990). Organizations Management reasoning, communications protocol, policies, and customs cooperate to create the uniqueness of each organization. Individuals join an organization or look for employment within a particular industry when the way of life is engaging. Be that as it may, changes in the cultural attributes of a few businesses have prompted changes in the organizations inside them. Culture changes, regardless of whether through growth, new administration or financial and regulatory interventions, make some employees leave to locate a more suitable organizational culture for themselves (Stum, 1998). The supplement of culture is structure, which is formed by culture and innovation. The structure begins with job design and workflow patterns and incorporates approaches and techniques, ranges of control, announcing connections and different elements that manage how to function is to be done and business conducted. IBM and Apple Computer Inc., for instance, make and sell computing equipment however have extremely disparate societies or structures (Clark, 2013).

From the institutional development point of view, the idea of institutional culture proposes an avenue for encouraging changes in conduct and attitudes with a specific end goal to achieve desired outcomes. Be that as it may, to do this effectively, institutional development specialists must see if they can foresee certain practices and dispositions in light of examples of institutional culture.

Supporters of strategic cultural change typically make a number of important assumptions. To start with, organizations have noticeable cultures, which impact quality and performance. Secondly, as much as a few cultures might be resistant to transform they are to some degree pliable and manageable. Thirdly, it can be recognized as particular cultural attributes that encourage or hinder good performance, and it should, accordingly, be achievable for leaders to design strategies for cultural change. Lastly, it is expected that any rewards accumulating from the change will exceed any dysfunctional problems. Employee retention might be encouraged by employer-employee relationships that permit the achievement of corporate financial objectives and also take into account employee needs (Onah \& Anikwe, 2016). Research has demonstrated that employee retention influences how well the organization performs from various perspectives. In the event that things being what they are employee retention shifts in certain anticipated courses starting with from one cultural pattern to another, organizational development experts could attempt to reinforce employee loyalty and in this way, organizational effectiveness by changing the organizational culture. These studies and anecdotal evidence propose a positive connection between solid organizational cultures and employee retention (Clark, 2013).

\subsection{Communication}

Efficient and effective communication has emerged from the extensive literature review as a fundamental aspect of human resource management, be it communication of organizational objectives, vision, procedures and business strategies or communication of facts, data and information communication structure (Songsern, 2014). Viable communications strengthen employee identification with the organization and build trust.

For organizational achievements, a standard two-way communication, particularly up close and personal with employees, was recognized as an imperative factor in building up trust and a feeling of being esteemed. Basically, two-way communication is viewed as a central management competency and as a vital administration obligation. For instance, the management obligations regarding for effective communication incorporate (1) guaranteeing individuals are informed on key issues, (2) conveying genuinely and as completely as conceivable on all issues influencing the all employees, (3) urging colleagues to talk about organization issues and give upward input and (4) guaranteeing issues from colleagues are encouraged back to senior administration and opportune answers are given (Fourtou, 1997; Mumford \& Hendricks, 1996).

Research led by Samihah (2014) uncovered that effective organizations place incredible accentuation on communication channels that empower employees at all levels to impart. Numerous formal and casual communication instruments exist; all intended to cultivate a situation of open exchange shared learning, downward, horizontal and cross-functional structure. General employee gatherings and different updates enable employees to change their efforts to aid organizational objectives. Opportunities for input give employees an avenue to impact their work and organizational policies. Grievance procedures provide a better and more formalized way by which employees can be heard when they are not satisfied with a decision or its outcome (Shields, 2017).

\subsection{Team Working Relationships}

Employees remain in the organization when strong relationships with their employers exist (Clark, 2013). Effective organizations today foster team building, project assignments including work with other employees and open doors for social collaboration both on and off their jobs or assignments (Marchington, 2000). One important value of team-based organizations is the bond they set up among employees. As Ray (1987) put it, "discussing stress in the workplace may give employees a feeling of camaraderie and that increases the value 
of the importance of their workplace".

Co-worker supportiveness alludes to the kind disposition of and the degree to which colleagues focus on fellow colleague remarks and concerns (Salisu et al., 2017). Communications with co-workers may serve "an affective- psychological function by providing emotional support against the stresses of the organization's socialization initiatives and uncertainties of the work setting". What's more, trying different things in different ways enables employees to deal with their work and individual life issues (Perry-Smith \& Blum, 2000). Numerous organizations have effectively created employee well-disposed environment by incorporating specialized work arrangements such as flexible working hours, adaptable working hours, working from home, and family-leave to help employees in making a work/life adjust. Some research scholars propose that for positive work encounters to expand loyalty significantly, employees must trust that such work encounters are an after effect of viable organization strategies and policies (Onah \& Anikwe, 2016). In this way, parlaying a valuable culture into expanded duty may rely upon how well managers prevail at inspiring employees to credit good management for their positive experiences.

Earlier research in organizational behaviour and human resource management has demonstrated that an organizations duty to enhancing relationships with its employees makes a more dedicated and mindful workforce (Eisenberger, Fasolo, \& Davis-LaMastro, 1990; Moorman, Blakely, \& Niehoff, 1998; Shore \& Wayne, 1993).

\subsection{Organizational Commitment}

The explanation behind the pervasive enthusiasm for the organization commitment concept in the field of organizational behaviour has been its accepted association with employee turnover. Throughout the years, it is conceived as the most recognized and examined construct of employee retention or loyalty to organizations. In academic research, the notion of organizational commitment is extensively used to allude to antecedents and outcomes, and in addition to the becoming committed or attached (O'Reilly \& Chatman, 1986).

The authors distinguished varieties in the meanings of organization among the different studies. The number of various definitions reveals insight into the way that no genuine agreement exists with respect to the construct of organizational commitment. As a result, organization commitment can be viewed as a multidimensional concept that has been interpreted in a wide range of ways (Meyer, 2012). The principle contenders seem, by all accounts, to be affective or attitudinal (Mowday, Steers, \& Porter, 1979; Porter, Steers, Mowday, \& Boulian, 1974) normative (Meyer, 2012), behavioural (Staw, 1980) and calculative. In a general sense, the meaning of organizational commitment depends on the idea that dedicated employees want to stay utilized with their organization (Meyer, 2012).

With respect to organizational commitment, research scholars contrast based on connection. Meyer (2012) recommend that "organizational commitment develops because of experiences of satisfying employees needs, inspiration and additionally are compatible with their qualities". They include that if organizations better deal with the experience of the employees that they might have the capacity to cultivate the development of the employee's responsibility.

As per Porter et al. (1974), organizational commitment is a "solid belief in, and acknowledgment of the organization's mission and objectives, an eagerness to apply impressive exertion for the benefit of the organization, and an unmistakable want to keep up organizational commitment". Given that values assume an imperative part in the meaning of organizational commitment, it makes sense that an individual whose individual qualities coordinate the working values of the organization would be more committed to the organization than an individual whose values contrast from the organization.

The most prevalent technique for testing this idea is through a person's mentalities and sentiments towards his or her employer. Legge (1995) says that "for all intents and purposes all the all the studies carried out on organizational commitment, in essence, have utilized the attitudinal conceptualization." The conceptualization proposes that committed employees have a solid confidence in, and acknowledgment of the organization's objectives and values, demonstrate a readiness to apply extensive commitment for the organization and want to stick to the organization (Cook \& Wall, 1980; Mowday et al., 1979).

The elements of organizational commitment analyzed in the present study, incorporates identification (Banai \& Reisel, 1993) and reciprocity with the organization, as well as intentions to stay committed to the organization. As per Meyer (2012) "employees with strong affective commitment remain in light of the fact that they need to, those with strong continuance commitment because they have to, and those with strong normative commitment because they believe they should do as such".

The accompanying terms are attributed to every one of the three types of commitment by Meyer (2012):

I. Affective Commitment: alludes to employees' passionate connection to the organization. As employees accumulate positive on the job experience, affective commitment is enhanced. As per some research scholars, for positive work encounters to build responsibility fundamentally, employees need to trust that such on-thejob experiences are a consequence of compelling management approaches.

ii. Duration Commitment: in light of the costs that employees connect with leaving the organization. An elevated level of continuance commitment may well keep an employee tied $t$ an organization; be that as it may, it is probably not going to deliver produce high productivity. As indicated by Meyer (2012), employees who 
demonstrated a high level of continuance commitment will probably earn below acceptable marks from their employers on performance and potential.

iii. Normative Commitment: involves employees' sentiments of commitment to stay with the organization. A feeling of commitment to stay with an organization is developed from familial and societal standards before an employee is engaged with an organization. Development of normative commitment likewise may come about because of organizational socialization, particularly in organizations that esteem loyalty and that deliberately and reliably impart that value to employees. In their review, Meyer (2012) observed a positive connection between affective commitment and employee retention. Both affective and continuance (calculative) commitment are expected to improve the probability that an individual will stay with an organization (Meyer, 2012). Notwithstanding, the purposes behind this vary amongst affective and continuance commitment. Employees with large amounts of affective commitment remain in an organization "on the grounds that they need to", though the individuals who have a strong continuance remain in light of the fact that they "need to." On the other hand, Wiener and Vardi (1980) found a negative relationship between normative commitment and employee retention. An investigation by John, Allen, and Smith (1993) found that affective and normative were negatively related to intention to quit. Some research scholars (e.g (Mathieu \& Zajac, 1990; Wiener \& Vardi, 1980)) nonetheless, found a weak direct relationship between organizational commitment and employee retention. Their investigations support organizational commitment as intervening and moderating turnover expectation. Precisely, employee commitment to an organization is seen as a basic achievement factor in the present professional workplace. The focus directed at employees by an organization is exhibited by the fiscal and non-financial advantages they get and the service that is dedicated to them (Clark, 2013). In the event that employees believe the organization is less committed to them then they may react by feeling less dedicated to the organization. This absence of employee commitment to the organization will be reflected in their intention to stay or leave (Meyer, 2012).

\subsection{Research Hypotheses} testing:

Based on the review of the literature, the following research hypotheses have been put forward for

$\mathrm{H}_{1}$ : Organizational leadership is positively related to employee retention

$\mathrm{H}_{2}$ : Organizational policies is positively related to employee retention

$\mathrm{H}_{3}$ : Communication is positively related to employee retention

$\mathrm{H}_{4}$ : Team working relationships is positively related to employee retention

$\mathrm{H}_{5}$ : Organizational commitment is positively related to employee retention

\section{Methodology}

The research employed a survey strategy in which primary quantitative data was gathered by means of a self-administered questionnaire applied directly to the research population via convenience sampling in a cross-sectional design over a two-month period. The research population were made up of all 411 employees working in the Civil services ministry in Oman as at the time of the survey. The unit of analysis is the individual unit, because the research is interested in the individual employee and their perceptions.

The questionnaire was subjected to pre-tests. Validity and reliability tests were carried out on the data retrieved from a pilot survey of 41 respondents prior to the main survey. These 41 respondents that took part in the pilot study were not included in the main survey. The pilot data were subjected to Cronbach's alpha test, Kaiser-Meyer-Olkin (KMO) measure of adequacy and Bartlett's test of sphericity. Cronbach's alpha was calculated to measure the internal consistency and reliability of the items. The Cronbach's alpha found to range between 0.791 and 0.833 for the section $\mathrm{B}$ of the questionnaire which was made up of measurement scales relating to organizational factors, thus the instrument of current study was considered to be reliable. KMO test was carried out to measure the homogeneity of variables and Bartlett's test of sphericity was done to test for the correlation among the variables used in the study. The KMO value was 0.772 , which is acceptable as a middling value. The Bartlett's test showed significant results and consequently the questionnaire instrument was accepted for further study.

In carrying out the data analysis for the main survey, the steps recommended by Cavana, Delahaye, and Sekaran (2001) was followed, these steps involved; preparing the data for analysis, getting a feel for the data, checking goodness of the data, and then testing hypotheses. In preparing the data for analysis, the data gathered were subjected to checking for correct data input and handling missing data; handling blank responses, coding and categorization of data. Spearman's correlation analysis was used to test the research hypotheses. This study is a correlational type of study. It examines the relationships between certain organizational factors and employee retention. Hence, using Correlation analysis enables the description of the relationship between each of those organizational factors and employee's retention

\section{Data Analysis}

\subsection{Socio-Demographic Characteristics}

In summary, the socio-demographic characteristics of the survey respondents according to gender, age, 
marital status, years of experience, level of education and monthly income reveals the following; Out of a total of 236 survey respondents, the majority of participants were male at $55.5 \%$ compared to $44.5 \%$ females showing a relative balance within the Ministry. The majority of the participants (39.2\%) were between 30 to 34 years old. In terms of marital status, the majority of the participants (84\%) are married. In terms of educational level, the majority of participants were bachelor holders (BSc.) with $72.2 \%$. Regarding the years of experience, the highest percentage of the survey respondents $(32.6 \%)$ are those who have been working for 6 to 10 years, and the lowest for those who work more than 20 years $(7.8 \%)$. While the information regarding the monthly income of the survey respondents show that the overall percentage of the participants with monthly income between 501 and 1000 OR was $79.3 \%$ followed by $9.2 \%$ of the participants with income between 200 and 500 OR. Approximately $8 \%$ of the participants have income between 1001 and 1500 OR. These can be considered as having high income.

\subsection{Descriptive Statistics of Research Variables}

Table 1 shows the mean scores and standard deviation of each organizational factor and employee retention.

Table-1. Descriptive Statistics of research variables.

\begin{tabular}{l|l|l|l}
\hline Constructs & $\mathbf{N}$ & Means & Std. Deviation \\
\hline Organizational leadership & 236 & 2.94 & 0.63 \\
\hline Organizational policies & 236 & 2.96 & 0.99 \\
\hline Communication & 236 & 2.54 & 0.87 \\
\hline Team working relationships & 236 & 3.07 & 0.85 \\
\hline Organizational commitment & 236 & 2.94 & 0.71 \\
\hline Employee retention & 236 & 3.01 & 1.42 \\
\hline
\end{tabular}

\subsection{Correlation Analysis}

The nonparametric correlations table gives a visual display of the correlation coefficients, significance values, as well as the number of cases with non-missing values. As shown in the Table 2, revealing the nonparametric correlations, the researcher reviewed the information from Spearman's rho utilizing the ranks of the data to compute the correlation coefficients. Spearman's rho is a rank-order correlation coefficient which is used to measure relationships at the ordinal level. This is a value of the correlation coefficient ranging from -1 to 1 . The sign of the correlation coefficient gives an indication of the direction of the relationship (positive or negative). The absolute value of the correlation coefficient indicates the strength, with larger absolute values indicating which variables are stronger.

Table-2. Correlation analysis of research variables.

\begin{tabular}{|c|c|c|c|c|c|c|c|}
\hline & & $\begin{array}{l}\text { Employee } \\
\text { retention }\end{array}$ & $\begin{array}{l}\text { Organizationa } \\
1 \text { leadership }\end{array}$ & $\begin{array}{l}\text { Organizationa } \\
1 \text { policies }\end{array}$ & $\begin{array}{l}\text { Communicat } \\
\text { ion }\end{array}$ & $\begin{array}{l}\text { Team } \\
\text { working } \\
\text { relationships }\end{array}$ & $\begin{array}{l}\text { Organization } \\
\text { al } \\
\text { commitment }\end{array}$ \\
\hline \multirow{3}{*}{$\begin{array}{l}\text { Employee } \\
\text { retention }\end{array}$} & Spearman's rho & 1.00 & & & & & \\
\hline & Sig (1 tailed) & & & & & & \\
\hline & $\mathrm{N}$ & 236 & & & & & \\
\hline \multirow{4}{*}{$\begin{array}{l}\text { Organizational } \\
\text { leadership }\end{array}$} & Spearman's rho & $0.274 * *$ & & & & & \\
\hline & Sig (1 tailed) & 0.001 & & & & & \\
\hline & $\mathrm{N}$ & 236 & & & & & \\
\hline & Spearman's rho & $0.358 * *$ & $0.242^{*}$ & & & & \\
\hline \multirow{3}{*}{$\begin{array}{l}\text { Organizational } \\
\text { policies }\end{array}$} & Sig (1 tailed) & 0.001 & 0.031 & & & & \\
\hline & $\mathrm{N}$ & 236 & 236 & & & & \\
\hline & Spearman's rho & $0.423 * *$ & $0.064 * *$ & $0.114^{* * *}$ & & & \\
\hline \multirow[t]{3}{*}{ Communication } & Sig (1 tailed) & 0.006 & 0.032 & 0.000 & & & \\
\hline & $\mathrm{N}$ & 236 & 236 & 236 & & & \\
\hline & Spearman's rho & $0.403 * *$ & $0.147^{*}$ & $0.109^{*}$ & $0.356^{* *}$ & & \\
\hline \multirow{2}{*}{$\begin{array}{l}\text { Team working } \\
\text { relationships }\end{array}$} & Sig (1 tailed) & 0.002 & 0.012 & 0.011 & 0.002 & & \\
\hline & $\mathrm{N}$ & 236 & 236 & 236 & 236 & & \\
\hline \multirow{3}{*}{$\begin{array}{l}\text { Organizational } \\
\text { commitment }\end{array}$} & Spearman's rho & $0.465 * *$ & $0.019^{* *}$ & $0.221^{*}$ & $0.156^{*}$ & $0.141^{*} *$ & \\
\hline & Sig (1 tailed) & 0.001 & 0.001 & 0.031 & 0.013 & 0.002 & \\
\hline & $\mathrm{N}$ & 236 & 236 & 236 & 236 & 236 & \\
\hline
\end{tabular}

From the results of the correlation analysis, the following findings are deduced; There was a significant relationship between employee retention and all the organizational factors teste. The Spearman's correlation coefficient between the organizational factors and employee retention ranged from 0.236 to 0.465. There was a positive relationship between organizational leadership and employee retention $(r=0.274, p<.01)$, 
organizational policies and employee retention $(\mathrm{r}=0.358, \mathrm{p}<.01)$, communication and employee retention $(\mathrm{r}=$ $0.423, \mathrm{p}<.01)$, team working relationships and employee retention $(\mathrm{r}=0.403, \mathrm{p}<.01)$, organizational commitment and employee retention $(\mathrm{r}=0.465, \mathrm{p}<.01)$. These results support the five research hypotheses

\subsection{Summary of Hypotheses Testing}

The summary from the hypotheses testing is presented in the Table 3

Table-3. Summary of hypotheses testing.

\begin{tabular}{l|l|l|l}
\hline $\mathbf{H}_{\mathrm{A}}$ & Hypotheses & Method of testing & Remarks \\
\hline $\mathrm{H}_{1}$ & Organizational leadership is positively related to employee retention & Correlation analysis & Supported \\
\hline $\mathrm{H}_{2}$ & Organizational policies is positively related to employee retention & Correlation analysis & Supported \\
\hline $\mathrm{H}_{3}$ & Communication is positively related to employee retention & Correlation analysis & Supported \\
\hline $\mathrm{H}_{4}$ & Team working relationships is positively related to employee retention & Correlation analysis & Supported \\
\hline $\mathrm{H}_{5}$ & Organizational commitment is positively related to employee retention & Correlation analysis & Supported \\
\hline
\end{tabular}

\section{Conclusion}

The data analysis carried out via Spearman's correlation in indicated significant relationships between organizational factors (organizational leadership, organizational policies, communication, team working relationships, organizational commitment) and employee retention. The tested hypotheses are summarized in Table 3. The results of these tested relationships in the context of the ministry of civil service in Oman is in agreement with the literature. For example, Alimo-Metcalfe and Alban-Metcalfe (2001) found that the organization leadership has a positive influence on employee's retention. The results of the current study agree with these findings, a positive experience with their leaders may determine their intentions to stay with the ministry. Also, Sheridan (1992) as well as Judge and Cable (1997) in their studies found that employees were more attracted to work in specific organizations because of its culture and policy. Kenneth (2001) discovered that employees tend to stay in the organization if they have good relations with their colleagues and he found that effective communication encouraged employees to remain with the organization as they feel that they are a part of the organization. Also, illustrate a strong relationship between employee's commitment and their decision to leave or stay in the organization. The study results showed that team relationships and interaction have an effect on employee retention. Recognition of effective team leaders is especially important. In addition, communication, most particularly in regard to the supervisor being available when help was necessary was very important. With the issues that have been highlighted within the study, especially those regarding leadership and the competency and appropriateness of the leaders, this is an important point to note on reasons for employee retention. The research is not causal and therefore not predictive. It looks at correlation because correlations analysis is computed to determine relationships between the study's variables. The study does not examine the complex cause and effect relationships between variables as this fall beyond the scope of the proposed study and may be a topic for further research

\section{References}

Alimo-Metcalfe, B., \& Alban-Metcalfe, R. J. (2001). The development of a new transformational leadership questionnaire. Journal of Occupational and Organizational Psychology, 74(1), 1-27.

Banai, M., \& Reisel, W. D. (1993). Expatriate managers' loyalty to the MNC: Myth or reality? An exploratory study. Journal of International Business Studies, 24(2), 233-248.

Bryman, A. (1992). Charisma and leadership in organizations. Newbury, C.A: Sage Publications.

Cavana, R. Y., Delahaye, B. L., \& Sekaran, U. (2001). Applied business research: Qualitative and quantitative methods (pp. 89). Milton: John Wiley and Sons Australia Ltd.

Chitsaz-Isfahani, A., \& Boustani, H. R. (2014). Effects of talent management on employees retention: The mediate effect of organizational trust. International Journal of Academic Research in Economics and Management Sciences, 3(5), 114128.

Clark, D. B. (2013). Employee commitment and other factors that affect attraction and retention of employees in organizations: The examination of research and OPM practices: University of Maryland University College.

Cook, J., \& Wall, T. (1980). New work attitude measures of trust, organizational commitment and personal need nonfulfilment. Journal of Occupational Psychology, 53(1), 39-52.

Eisenberger, R., Fasolo, P., \& Davis-LaMastro, V. (1990). Perceived organizational support and employee diligence, commitment, and innovation. Journal of Applied Psychology, 75(1), 51-57.

Fitz-enz, J. (1990). Getting and keeping good employees. Personnel, 67(8), 25-29.

Fourtou, J. (1997). The passionate leader. Measuring Business Excellence, 1(2), 24-28.

Islam, R., \& Ismail, A. Z. (2008). Employee motivation: A Malaysian perspective. International Journal of Commerce and Management, $18(4), 344-362$.

John, P. M., Allen, N. J., \& Smith, C. A. (1993). Commitment to organizations and occupations: Extension and test of a three-component conceptualization. Journal of applied psychology, $78(4), 538$.

Judge, T. A., \& Cable, D. M. (1997). Applicant personality, organizational culture, and organization attraction. Personnel Psychology, 50(2), 359-394. 
Kenneth, F. C. (2001). What businesses are doing to attract and retain employees--becoming an employer of choice. Employee Benefits Journal, 26(1), 21-23.

Legge, K. (1995). What is human resource management?. In Human resource management (pp. 62-95). London: Palgrave.

Marchington, M. (2000). Teamworking and employee involvement: Terminology, evaluation and context. Team working (pp. 60-80). London: Macmillan.

Mathieu, J. E., \& Zajac, D. M. (1990). A review and meta-analysis of the antecedents, correlates, and consequences of organizational commitment. Psychological Bulletin, 108(2), 171-194.

Meyer, J. P. (2012). Commitment in a changing world of work. In commitment in organizations (pp. 60-91): Routledge.

Moorman, R. H., Blakely, G. L., \& Niehoff, B. P. (1998). Does perceived organizational support mediate the relationship between procedural justice and organizational citizenship behavior? Academy of Management Journal, 41(3), 351357.

Mowday, R. T., Steers, R. M., \& Porter, L. W. (1979). The measurement of organizational commitment. Journal of Vocational Behavior, 14(2), 224-247.

Muleya, D., Ngirande, H., \& Rachidi, M. P. (2016). Human resource practices as determinants of employees' Intention to leave: A study from a selected South African institution. Investment Management and Financial Innovations, 13(3), 403-409.

Mumford, E., \& Hendricks, R. (1996). Business process re-engineering RIP. People Management, 2(9), $22-27$.

O'Reilly, C. A., \& Chatman, J. (1986). Organizational commitment and psychological attachment: The effects of compliance, identification, and internalization on prosocial behavior. Journal of Applied Psychology, 71(3), 492-499.

Onah, F. O., \& Anikwe, O. S. (2016). The task of attraction and retention of academic staff in Nigeria Universities. Journal of Management and Strategy, 7(2), 9-20.

Perry-Smith, J. E., \& Blum, T. C. (2000). Work-family human resource bundles and perceived organizational performance. Academy of Management Journal, 43(6), 1107-1117.

Porter, L. W., Steers, R. M., Mowday, R. T., \& Boulian, P. V. (1974). Organizational commitment, job satisfaction, and turnover among psychiatric technicians. Journal of Applied Psychology, 59(5), 603-609.

Ray, E. (1987). Supportive relationships and occupational stress in the workplace. Communicating Social Support, 172-191.

Salisu, J. B., Chinyio, E., \& Suresh, S. (2017). The impact of compensation on public construction workers' retention in Jigawa State of Nigeria. International Journal of Engineering Sciences \& Management Research, 6(2), 17-30.

Samihah, S. (2014). The mediating effect of job satisfaction on the relationship between HR practices and employee retention among generation $Y$. Doctoral Dissertation, Univeristi Utara Malaysia

Shekshnia. (1994). Managing people in Russia challenges for foreign investors. European Management Journal, $21(3)$, 441 498.

Sheridan, J. E. (1992). Organizational culture and employee retention. Academy of Management Journal, 35(5), 1036-1056.

Shields, R. (2017). The role of perceived organisational support and the impact of its constructs on teacher retention. Doctoral Dissertation, University of Pretoria.

Shore, L. M., \& Wayne, S. J. (1993). Commitment and employee behavior: Comparison of affective commitment and continuance commitment with perceived organizational support. Journal of Applied Psychology, 78(5), 774-780.

Sinha, C., \& Sinha, R. (2012). Factors affecting employee retention: A comparative analysis of two organizations from heavy engineering industry. European Journal of Business and Management, 4(3), 145-162.

Songsern, K. (2014). The impact of OD intervention on the factors of job characteristic, career opportunities \& advancement, salary \& benefit, and managers' leadership style that influence job satisfaction and nurse retention in two private hospitals: A case study. ABAC Odi Journal Vision. Action. Outcome, 1(1).

Staw, B. M. (1980). The consequences of turnover. Journal of Occupational Behaviour, 1(4), 253-273.

Stum, D. L. (1998). Five ingredients for an employee retention formula. In HR Focus, 75(9), 9-11.

Wiener, Y., \& Vardi, Y. (1980). Relationships between job, organization, and career commitments and work outcomes—an integrative approach. Organizational Behavior and Human Performance, 26(1), 81-96. 